\title{
Developing the objective and the scope of the ecological footprint assessment project
}

\author{
Ivan Mihajlović \\ Engineering management department \\ University of Belgrade, Technical \\ faculty in Bor \\ Bor, Serbia \\ imihajlovic@tfbor.bg.ac.rs
}

\author{
Isidora Milošević \\ Engineering management department \\ University of Belgrade, Technical \\ faculty in Bor \\ Bor, Serbia \\ imilosevic@tfbor.bg.ac.rs
}

\author{
Nada Štrbac \\ Metallurgy department \\ University of Belgrade, Technical \\ faculty in Bor \\ Bor, Serbia \\ nstrbac@tfbor.bg.ac.rs
}

\begin{abstract}
Besides technological and economic aspects, environmental segments are gaining equal importance in planning, realization and control of contemporary project ventures. This manuscript is presenting the frame and the scope of the project for the ecological footprint assessment. The realization of some phases of this project has already begun, while most of the remaining phases are still at the preparation stage.
\end{abstract}

Keywords-ecological footprint, project planning, awareness, global and local aspects

\section{INTRODUCTION}

Contemporary project management is equally concerned with the systematic influence of technological, economic and environmental aspects of each new project venture. This issue is becoming more and more elaborated with the projects concerned with contemporary industry and especially in the aspect of Industry 4.0 paradigm. Accordingly, project managers are increasingly accounting for the environmental aspects of their initiatives [1].

It is also important to point out that the global industry increased consumption and waste, and in turn, reduced the natural capital [2]. In order to support human needs and industrial activities, the world loses its biodiversity, its forests, land and water. The United Nations listed 17 sustainable development goals to reach by 2030, among which is the protection of the planet, in particular sustainable production and consumption, efficient use of natural resources and working towards reducing the effects of climate change [3]. This as well has to be the target values of each new project venture, besides achieving the usual main project goals and objectives such are , finishing the project within the scheduled time plane, finishing the project within the scheduled budget, finishing the project at the predefined level of quality and efficiency in resources utilization.

Having in mind the wide variety and differences, resulting from the complexity of contemporary production processes, it is difficult to define the unique measure to assess the environmental burden of each industrial projects. Having this in mind, the approach of environmental assessment has moved from the processes to the products and services. Namely, instead of measuring the environmental aspects of processes and projects, it is more convenient to assess the ecological footprint of each of the product (and/or service) they generate. This way, Ecological Footprint (EF) has resulted as the universal tool to assess the environmental burden of any existing human activity.

The early start of ecological footprint (EF) development and analysis, begun during the 1990s in order to measure human demand on nature $[2,4,5]$. In particular, ecological footprint presents the capacity of natural resources needed to sustain and compensate the human activities [6]. It can be stated that, in a way, it represents a measure of sustainability, as it reflects the planet's available resources and the way they are used for human needs. Every activity in the world is impacting the Earth and its environmental capacity, hence this speaks in favour of the importance of ecological footprint evaluation and prediction.

An ecological footprint can be observed from two aspects: (1) ecological footprint of production, and (2) ecological footprint of consumption. The ecological footprint of production presents "the sum of the footprints for all resources harvested and all waste generated within one country" [7]. On the other hand, the ecological footprint of consumption presents the capacity of biologically productive area (biocapacity) that is needed for a total consumption by the population of the observed country [7]. The ecological footprint is measured in units of global hectares (gha).

Presenting it simply, the ecological footprint represents the material balance of the Earth, observed as closed system. This way, a state of ecological deficit occurs when the demand placed on the biosphere exceeds the region's bio-capacity to recover after all human activities. Unfortunately, at the global level, an equivalent of 1.7 Earths is used to provide the present resources that humanity needs [7]. This way, it is recorded that in August each year the human population exhaust available annual resources. In the period until the end of the year, we are spending the resources of future generations.

It can be stated that the industrial activities are based on smart and automated industrial concepts, and in most contemporary conditions, on Industry 4.0 concept which includes cyber-physical systems, the Internet of Things, cloud computing artificial intelligence, and cognitive computing. However, even such processes require resources and especially 
energy. As the industry becomes more environmentally friendly, consequently it also becomes more energy-dependent. This way, the pollution and environmental burden are now transferred from the production to the consumption sphere, especially when it comes to energy consumption [8].

Those facts have motivated the research presented in this manuscript. The idea was to develop the project that will be dealing with the analysis, measurements and evaluation of the ecological footprint on the local level in one region in Serbia. To be able to assess and influence the ecological footprint at the regional level, it was necessary to prepare the starting databases and base of knowledge on the subject of EF, at the global level. This way, the research can be classified as the "Think globally and act locally" paradigm [9]. Bases on the available global knowledge on the EF, the plan for its assessment and measurement on the local level was developed. Also, the important issue for the success of this kind of project activities, at the local level, is raising the awareness and obtaining the support from the local authorities, e.g. policymakers and decision-makers.

\section{LITERATURE REVIEW ON THE INDUSTRIAL}

ECOLOGICAL FOOTPRINT ASSESSMENT PROJECTS

Considering the importance of the EF assessment, both on local and the global level, there is a large body of references published on this topic. Some of the most important references, connected with the scope of the project described in this manuscript, will be presented here, as potential benchmarking sources of data.

Group of authors from Australia [10], was using the corporate sustainability reports to assess the environmental footprint of the copper mining industry. In their project, they were collecting the primary data from sustainability reports published by copper producing mines, operations and companies, from Australia, Chile, Peru, Argentina, Laos, Papua New Guinea, South Africa, Turkey, Finland, the USA and Canada. They were also targeting the evaluation of the EF influence of the contemporary copper production processes on the level of energy dependence and consumption. The typical range of energy intensity was found to be $10-70 \mathrm{GJ} / \mathrm{t} \mathrm{Cu}$, with an average of $22.2 \mathrm{GJ} / \mathrm{t} \mathrm{Cu}[10]$.

The international project team was also investigating the values of carbon footprint of $\mathrm{Cu}$ and $\mathrm{Zn}$ production, from primary and secondary sources [11]. For their research, they were using the data collected from the scientific literature and the Ecoinvent database [12]. In the research, they reviled the fact that the secondary production of $\mathrm{Cu}$ and $\mathrm{Zn}$ has the potential to be more beneficial compared to primary production regarding the impact on EF. However, they also concluded that technologies used today for the production of both metals from secondary resources are still immature, and more research on this topic is needed [12].
Also, some other industries were analysed in the research works and projects of other authors. Cagiao et al. [13], were performing the calculations of the corporate carbon footprint of the cement industry in Spain. Group of authors from China [14], were done assessment and calculations of the footprint generated in a typical steel production facility in their country. On the other hand, Sutton et al. [15] have performed the mapping and monetizing the human ecological footprint at the global level. In their research, they calculated the ecological footprint per capita, for deferent countries, and correlated this values with pavement (i.e., anthropogenically created impervious surface area or ISA) as a proxy measure of 'cost'.

All presented examples are speaking in favour of the fact that the EF is attracting large interest from different aspects of research of large number of investigators. On the other hand, this issue is still far from being adequately addressed in Serbia. Based on the wide reference search, it was concluded that there isn't any research project conducted in Serbia, aiming to assess and optimize the values of EF of industrial sector, on local or regional level. This represents a significant research gap that will be partially filled with the results of this research.

\section{THE OBJECTIVE AND THE SCOPE OF THE PROJECT}

The objective of this project is to develop the measuring scale that can be of use in the measurement of the environmental burden of the industrial facilities, through assessment of the ecological footprint of their main products and services. The measuring scale, developed in this project, will be of use in obtaining the clear picture in the level of ecological influence of the local public and private industrial and nonindustrial facilities. This will be starting base for the future strategical analysis of this issue, and for proposal of the real actions that can be used in further optimization of such processes, aiming to decrease their ecological footprint.

To be able to achieve such objective, the framework of the project scope had to be developed, that includes two main phases, in which the most important activities will be carried on. The representation of the time plan for the main project activities is given in Figure 1.

The idea of this project was generated through the realisation of another project: "developing the technological process for unconventional copper concentrates processing, aiming to decrease pollutants emission". This project is financed from the Ministry of education, science and technological development of the Republic of Serbia, starting from the year 2011.

The knowledge base generated, during the research on this project, was a starting point in the development of the project scope of this new venture. As presented in Figure 1, the work on the project activities of presented project, begun during December 2018. 


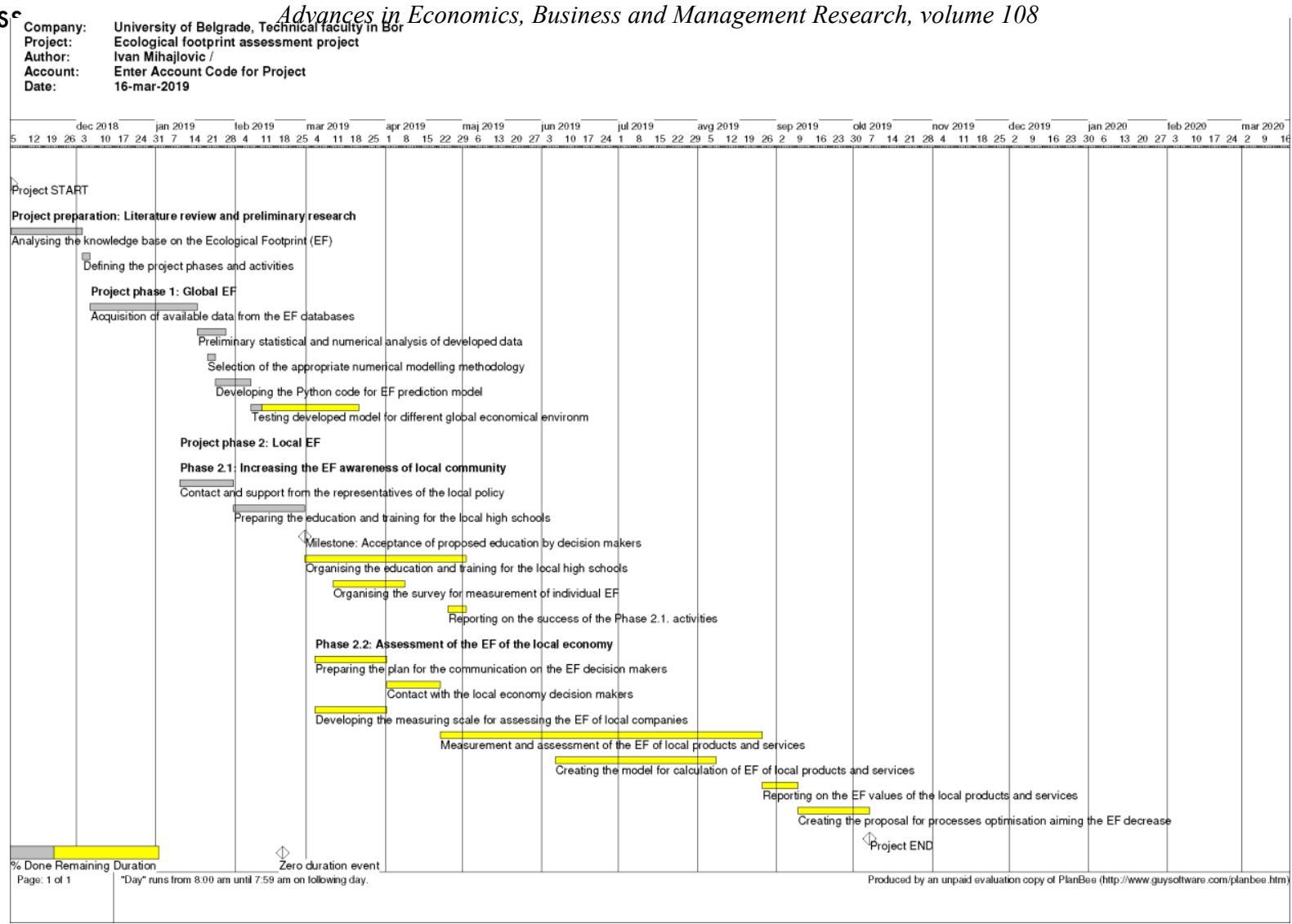

Fig. 1.Gantt chart of presented project

The preliminary stage of this project was the project preparation that included the analysis of the knowledge base on the Ecological Footprint. This stage was based on the wide research of the available scientific literature on this topic. As a result of this activity, it was possible to propose the preliminary design of the following project phases and activities.

The first stage of the project was dedicated to analysis and modelling of the Global EF parameters. To be able to get the real picture of the present EF level globally, as well as in different regions of the world, available data was acquired from the Global Footprint Network [16] and the World Bank open data [17].

In selecting the data to be analyzed, the authors have considered the fact that in contemporary industrial production, the environmental burden of the processes is not that much resulting from the direct emission of pollutants in the water, air or the land. Namely, contemporary processes are very much environmentally friendly, when it comes to direct pollution, especially in the concept of Industry 4.0, which is based on cyber-physical systems, the Internet of things, cloud computing, artificial intelligence, and cognitive computing. However, to be able to be such, contemporary production processes are heavily automated and computerized. This way, the processes become even more energy-dependent and are consuming large amount of electric energy. On the other hand, the electric energy is still largely produced based on combustion of fossil fuels, coal, and other non- renewable resources. This way, energy production is now becoming part of the production supply chain that is creating the largest environmental burden. Accordingly, it can be stated that the pollution centre of gravity is nowadays transferred from direct industrial production toward energy production facilities, which are required to sustain contemporary production processes.

Having all this in mind, the data for the analysis of the global EF, that was realized in this project, included the total ecological footprint (EF) of consumption (in gha) as an output variable, and energy consumption (kg of oil equivalent per capita); Electric power consumption ( $\mathrm{kWh}$ per capita); Population size (urban, rural, and total); GDP per capita (in USD) and energy production (with electric energy as presented example) from six different sources (in \% of total electricity production), as input variables. In particular, the ration of electricity production was analyzed depending on the used resources: (1) coal, (2) hydro, (3) nuclear, (4) renewable, (5) natural gas, and (6) oil. The real necessity of the research on this subject can be realized, in accordance with the EF values presented in Figure 2 and Figure 3. Figure 2, presents the global trend of the EF values, in the period 1971 until today. Figures $3 \mathrm{a}$ and $3 \mathrm{~b}$ are presenting the EF per capita trends and values in the two largest world's economies (United States of America and China, respectively), in the period 1961 to 2014. Based on the data available in presented figures, it is obvious that the $\mathrm{EF}$ values have the increasing level on the global scale, which mostly results from the fact that the leading world's economies are the trendsetters of the EF increase. This is leading to the global environmental situation that is far from acceptable and sustainable in the future. 


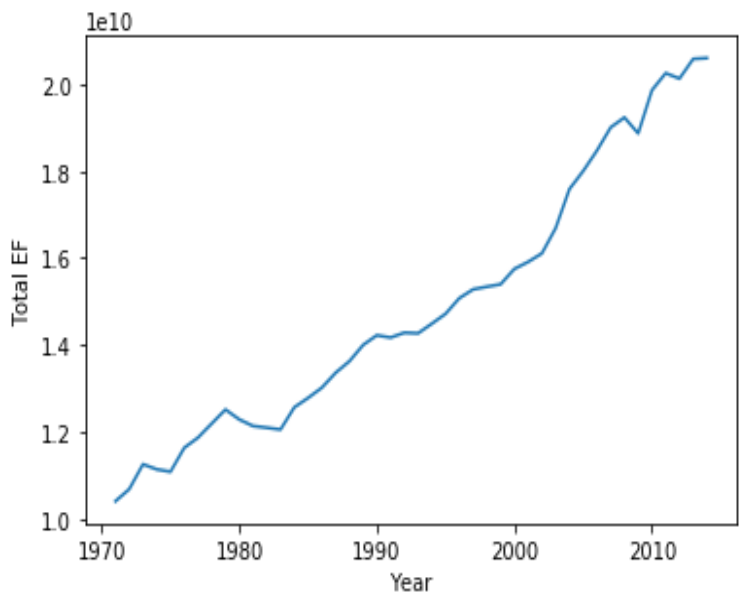

Fig. 2. Values of the measured global EF in gha for the period from 1971 until today [2]

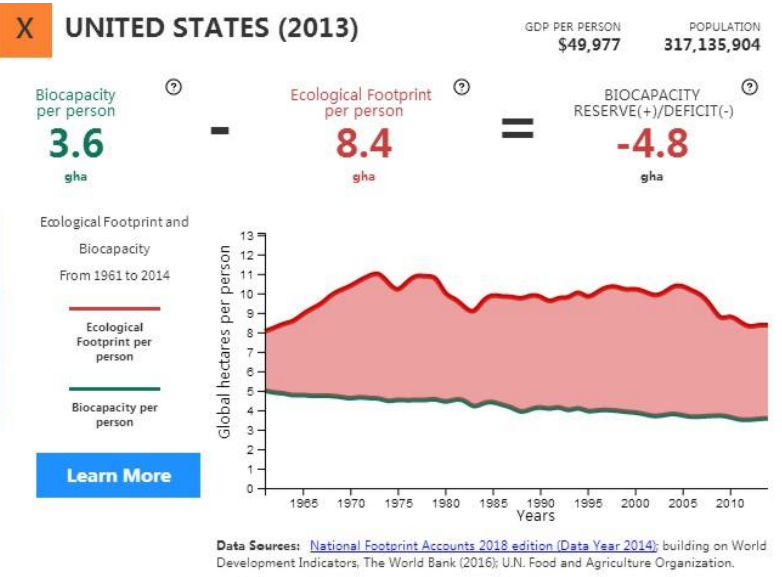

a) the linear (MLRA) and non-linear (ANNs) statistical analysis. The results of the prediction of the potential of the MLRA and ANN models are given in reference [8].

Obviously, both modelling procedures resulted in high prediction potential. Namely, using the statistical modelling, it is possible to evaluate the values of global EF, based on deferent set of input variables (Urban population size, GDP per Capita, Energy use and Electricity production), with the accuracy of $85 \%$ in case of MLRA and $97 \%$ with the ANN model. Further analysis included the Monte Carlo simulation and adjustment of developed models and prediction of the global EF values [8].

In the subsequent activities of this stage of the project, the influence off ratio of deferent sources used for electricity production, on the global EF values was

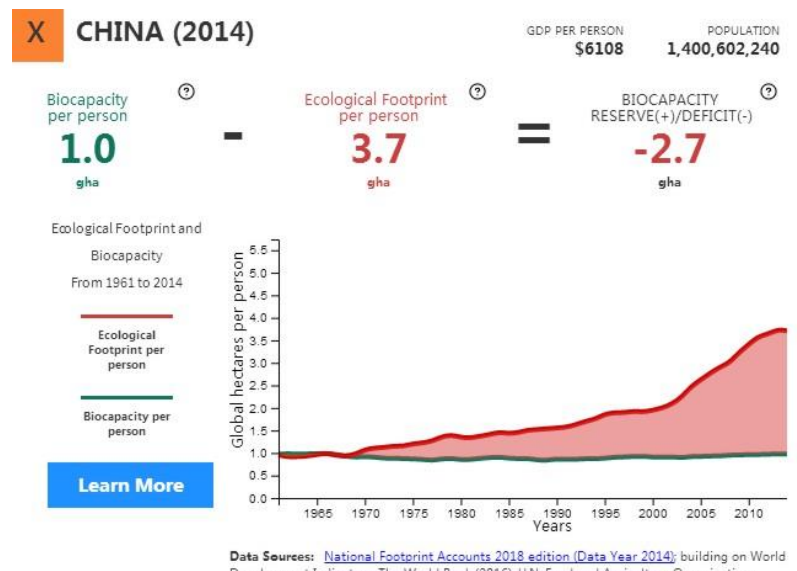

b)

Fig. 3. Values of the EF per capita in gha for the period 1971 until 2014, for the USA (a) and China (b) $[16,17]$

Most of the researchers would agree that the EF growing trend could be slowed down if the global energy consumption decrease, or if the energy production switches from fossil to renewable resources. On the other hand, is not realistic to expect that entire world will completely stop using energy or replace fossil fuels with renewable ones. Also, it should be noted that there are no exact calculations that can give the exact optimal proportion of the different energy sources rations required to change the trend of EF. This is why the first stage of this project was dedicated to analyses of the influence of ration of deferent energy sources that are used globally and regionally in energy production, on the values of EF. Research on this stage of the project has already begun, and some initial results are already available [2, 8]. Some of the most important findings will be given here.

In the first stage of this project, the development of the prediction model, that can be used for estimating the values of EF, based on the deferent set of input parameters (Urban population size, GDP per Capita, Energy use and Electricity production) was done using analyzed. Obtained results of this segment of modelling are published in reference [2]. Based on this results of the research, it was concluded that the values of the global EF can be predicted, with the $98 \%$ accuracy, based on the input variables which comprises: the ration of the electricity production from (1) coal, (2) hydro, (3) nuclear, (4) renewable, (5) natural gas, and (6) oil sources. After conducting the modelling and simulation calculations of EF values, based on the historical data from 1971 until today, the trend of EF values until the year 2025 was predicted (Figure 4).

Unfortunately, the results presented in Figure 4 are not optimistic. This speaks in favour that the global human population should initiate some real actions on decreasing the energy consumption or more intensive transferring to renewable sources as soon as possible, to be able to reverse the trend of EF growth.

As the direct result of this first stage of the project, one practical tool was created that can be used to calculate the values of $\mathrm{EF}$, based on the different combination of the input variables. The code for this 
GUI based application was developed in Python. The resulting GUI is given in Figure 5.

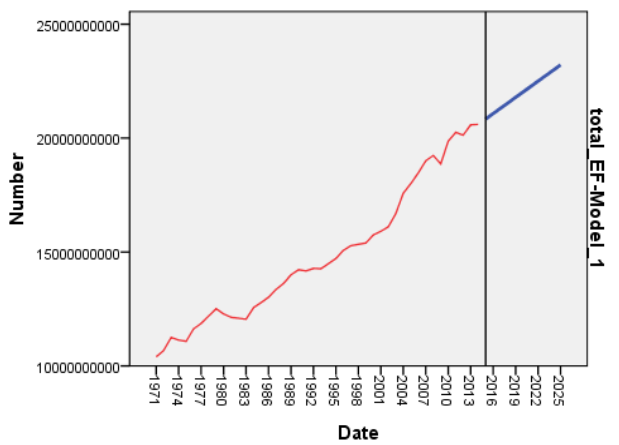

Fig. 4. Predicting the values of EC, based on the historical data on energy production from different sources [2]

However, considering the fact that our planet presents one closed system, global values of EF are actually the result of cumulative factors of the local national environmental burden accumulation. This way, any local action that will lead to a decrease of EF values, during production, would result in subsequent decrease of global EF. Basically, this speaks in favour organizational level and on the awareness of decisionmakers. Accordingly, the idea of the substage 2.1 of this project is to assess the level of awareness of local 二 - Foreceaspolicymakers and local population in the region of city of Bor, on EF. With this aim, the initial contact was done with the local policymakers (the representatives of local government) and also with representatives of the local high schools in city of Bor. The idea of this action is in development of the project activities that will be targeted on creating the survey, which will be used on collecting the level of awareness of local population on the ecological footprint. Also, this will be followed with the one-week training of university and high school students in Bor, on the importance of the EF and the influence of deferent human activities on the EF values. The plan is that this sub-stage of the project should be accomplished by the end of May 2019. The idea of the training organized for students is in assumption that, if they have higher awareness of influence of different technical aspects that can result with increase of $\mathrm{EF}$, maybe in the future their decisions will be more adequate compared with the decisions of previous generations. Namely, if the future engineer is clearly aware of the fact how the industrial activities are influencing the values of EF of

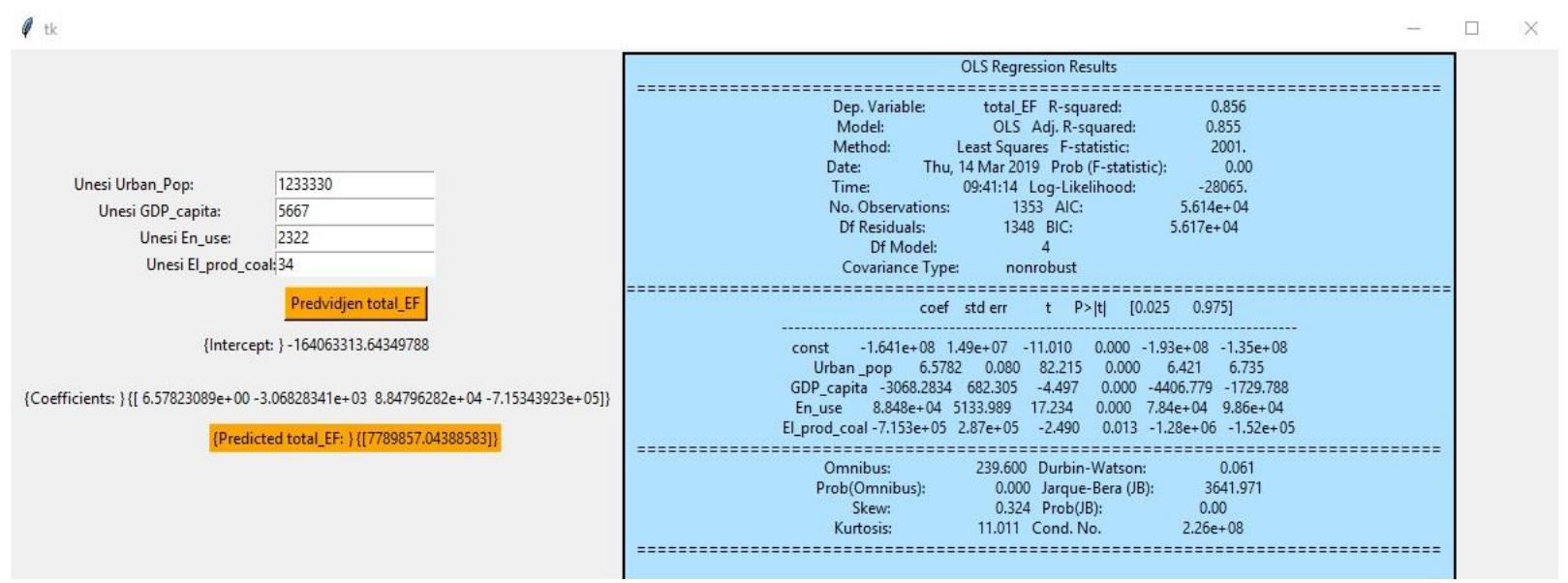

Fig. 5. GUI of developed tool for calculating the EF values based on different influential input parameters

of the idea:"If you want to change the world, start with your own backyard". Having this in mind, it was decided that the next stages of this project should be targeted in the direction of analyzing, assessing and decreasing the local levels of EF.

This way, in the second stage of this project, the authors were dealing with the Local EF. This phase is consisting of two sub-phases. The subphase 2.1 (in Figure 1) is dealing with increasing the EF awareness of local community. Namely, the idea of this stage results from the fact that city of Bor is representing one of the largest industrial facilities in our country. Having this in mind, besides large economic benefits that are resulting from this industrial activities, in more than 100 years, there are also some environmental issues that were accumulated during the years. Besides technical issues, ecological effects of industrial processes are also largely depending on the its products and services, this can influence his/her organizational decision making attitudes.

The second phase of this project also includes the sub-phase 2.2., which will be dedicated to measurements and assessment of the EF values of the local public and private companies. The idea of this phase is to develop the measuring scale that can be used to evaluate the $\mathrm{EF}$ generated through production or creation of services in the local public and private sector. Namely, based on the already existing measuring tools, developed by different authors $[4,5$, 10-15], the adjustments will be made to enable the calculation of the EF of the products and services from the local public and private companies in the region of city of Bor. This phase will result in a clear picture of the present EF of the local economy and with the values of EF per capita in this region. Following this analysis, the concrete measures for optimization will 
be developed, that will be offered to local decisionmakers, aiming to decrease the EF values in the future. This sub-phase of the project is planned to start in April 2018 and in the most optimistic scenario, should end by the end of this year. However, there is potential that this project could be much longer.

\section{CONCLUSIONS}

This paper is presenting the project for the EF assessment and awareness increase in the local and regional level, based on the facts collected on the global level. The project has consisted of two interconnected phases and many activities that will result in achieving its final goal. The main goals of the project are in development of the measurement tool that can be used to assess and calculate the EF of local economy, e.g. to calculate the values of the EF of the products and services in public and private companies in Serbia. Also, the aim is to increase the level of EF awareness of local population, and especially the high school and the university students, as future decisionmakers. Some initial stages of the project already started, and the first achieved results are presented here. Some stages of the project are being realized right now, and the remaining activities are planned to be completed until the end of this year.

The limitations of this research are in the fact that it is still in its initial phase and that, for now, it is limited to the local - regional level. After obtaining the final results of the project, on the regional level, the procedure of the project can be expanded to the national level and to even larger community. This will be the main task of our future research on this topic, which will be mainly correlated with the potential to find adequate financial support for this project research activities.

\section{ACKNOWLEDGEMENT}

Part of the research presented in this manuscript is resulting from the financing under the project of the Ministry of Education, Science and Technological Development of the Republic of Serbia: TR 34023.

\section{REFERENCES}

[1] A. Sboey, "Incorporating environmentalism into project management," Paper presented at PMI Global Congres 2013. New Orleans, Newtown Square, PA: Project Management Institute.
[2] R. Janković, I. Mihajlović, and N. Štrbac, "Modeling the influence of the energy sources and consumption on the resoulting ecological footprint," Paper accepted for the YOUng ResearcherS Conference - YOURS 2019.

[3] United Nations, Transforming our world: The 2030 agenda for sustainable development. Resolution adopted by the General Assembly, 2015.

[4] W. E. Rees, "Ecological footprints and appropriated carrying capacity: what urban economics leaves out". Environment and urbanization, vol. 4(2), 1992, pp. 121-130.

[5] M. Wackernagel, J. McIntosh, W. E. Rees, and R. Woollard, "How big is our ecological footprint". A handbook for estimating a community's appropriated carrying capacity. Vancouver, Canada, 1993.

[6] M. Wackernagel, L. Onisto, P. Bello, A. C. Linares, I. S. L. Falfán, J. M. Garcia, A. I. S. Guerrero, and M. G. S. Guerrero, "National natural capital accounting with the ecological footprint concept". Ecological economies, vol. 29(3), 1999, pp. 375-390.

[7] Global Footprint Network, Ecolocial footprint atlas 2010. Retrieved November, $\quad 25, \quad 2018$ (http://www.footprintnetwork.org).

[8] R. Janković, and I. Mihajlović, "Development and implementation of the numerical model for predicting the values of ecological footprint, based on the Monte Carlo methodology, "Book of proceedings of the FIKUSZ Symposium for young researchers, Obuda University, Budapest, Hungary, 2019.

[9] J. Parnell, "Reassessing the think global, act local mandate: evaluation and synthesis", Serbian Journal of Management, vol. 1(1), 2006, pp. 21-28

[10] S. Northey, N. Haque and G. Mudd, "Using sustainability reporting to assess the environmental footprint of copper mining", Journal of Cleaner Production, vol. 40, 2013, pp. 118-128.

[11] A. E. Nilsson, M. M. Aragones, F. A. Torralvo, V. Dunon, H. Angel, K. Komnitsas and K. Willquist, "A review of the carbon footprint of $\mathrm{Cu}$ and $\mathrm{Zn}$ production from primary and secondary sources, Minerals, vol. 7, 2017, pp. 1-12.

[12] Swiss Centre for Life Cycle Inventories. Ecoinvent Life Cycle Inventory Database v3.3; Ecoinvent: Zurich, Switzerland, 2016 .

[13] J. Cagio, B. Gomez, J.L. Domenech, S. G. Mainar and H. G. Lanza, "Calculation of the corporate carbon footprint of the cement industry by the application of MC3 methodology", Ecological indicators, vol. 11, 2011, pp. 1526-1540.

[14] Z. Qi, C. Gao, H. Na and Z. Ye, "Using forest area for carbon footprint analysis of typical steel enterprises in China", Resources, Conversation and Recycling, vol. 132, 2018, pp. 352-360.

[15] P. C. Sutton, S. J. Anderson, B. T. Tuttle and L. Morse, "The real wealth of nations: Mapping and monetizing the human ecological footprint”, Ecological indicators, vol. 16, 2012, pp. 11-22.

[16] Global Footprint Network. Ecological footprint. Footprint Network web site: http://www.footprintnetwork.org., Accessed June, 12, 2018. World Bank Open Data, https://data.worldbank.org. Accessed May, 23, 2018. 